\title{
Topical Application of a Regenerative Agent for the Treatment of Persistent Epithelial Defects after Penetrating Keratoplasty
}

Sonia $\mathrm{P}^{*}$

Hospital Garcia de Orta, EPE, Portugal

*Corresponding author: Sonia Parreira, Hospital Garcia de Orta, EPE, Av. Torrado da Silva 2805-267 Almada, Portugal, Tel: +351 914212043; Email: soniaparreira20@hotmail.com

\section{Case Report}

Volume 2 Issue 1

Received Date: February 27, 2017

Published Date: March 23, 2017

\section{Abstract}

Purpose: The aim of this study was to report two cases of persistent epithelial defects (PEDs) after penetrating keratoplasty successfully treated with topical application of a regenerative agent (RGTA; Cacicol ${ }^{20}$ )

Methods: This is a case series.

Results: Two patients suffering from a PED and unresponsive to conventional therapy were treated with application of Cacicol ${ }^{20}$. The PED healed in all patients and no side effects were noted.

Conclusions: Our cases show revealed that topical application of Cacicol ${ }^{20}$ may be used with success for the treatment of PED after PKP.

Keywords: Persistent epithelial defects; Penetrating keratoplasty; Neurotrophic keratitis; Diabetes mellitus; Ocular cicatricial pemphigoid.

\section{Introduction}

Persistent epithelial defect (PED) is defined as fullthickness loss of epithelial cells that do not show healing for more than 2 weeks despite conventional treatment [1,2]. PED may result from both ocular and systemic disorders, such as dry eye, chemical injury, microbial infection, neurotrophic keratitis, StevensJohnson syndrome, diabetes mellitus and ocular cicatricial pemphigoid. PEDs could lead to stromal degradation and thinning and in advanced cases, the cornea may perforate. One reason leading to PED is limbal stem cell deficiency (LSCD), which deprives the source of corneal epithelial regeneration. Even without LSCD, PED also occurs in $3.4 \%$ of eyes after penetrating keratoplasty (PKP) [3]. PED may lead to visionthreatening complications because of infection, ulceration, neovascularization and scarring and may hamper PKP survival $[4,5]$.

Several approaches have been proposed for the treatment of PEDs such as artificial tears, eye patching, punctal plugs, contact lens, autologous serum eye drops, amniotic membrane graft and tarsorrhaphy [6-10]. Regenerating agents (RGTAs) are a new pharmaceutical family of biodegradable glucose-based polymers engineered to replace heparan sulfates [11]. Cacicol20 belongs to the RGTA family that binds to matrix proteins and protects them from proteolysis; this permits the extracellular matrix microenvironment to restore its original architecture [11-13].

In this article, we present two patients with PEDs who were successfully treated with an RGTA (Cacicol ${ }^{20}$ ).

\section{Case Reports}

\section{Case}

A 79-year-old woman was monitored in our department due to a bullous keratopathy in her left eye, which was caused by a complicated cataract surgery. 


\section{Open Access Journal of Ophthalmology}

Her best corrected visual acuity (BCVA) was hand movements. She had undergone a PKP and after two weeks the slit-lamp examination showed an extended graft epithelial defect. The PED was resistant to conventional treatment for four weeks. Conventional therapy included pressure patch, topical antibiotic and steroid eye drops (ofloxacin and fluorometholone) and monodose artificial tears.

Due to treatment failure topical application of an
RGTA (Cacicol ${ }^{20}$ ) was prescribed (instillation of 1 drop in alternate days) with reduction of the previous treatment.

One week later the defect was reduced to half and four weeks after $\mathrm{Cacicol}^{20}$ commenced the slit-lamp examination showed complete corneal epithelial healing. There was no event of recurrence during the 6month follow-up.
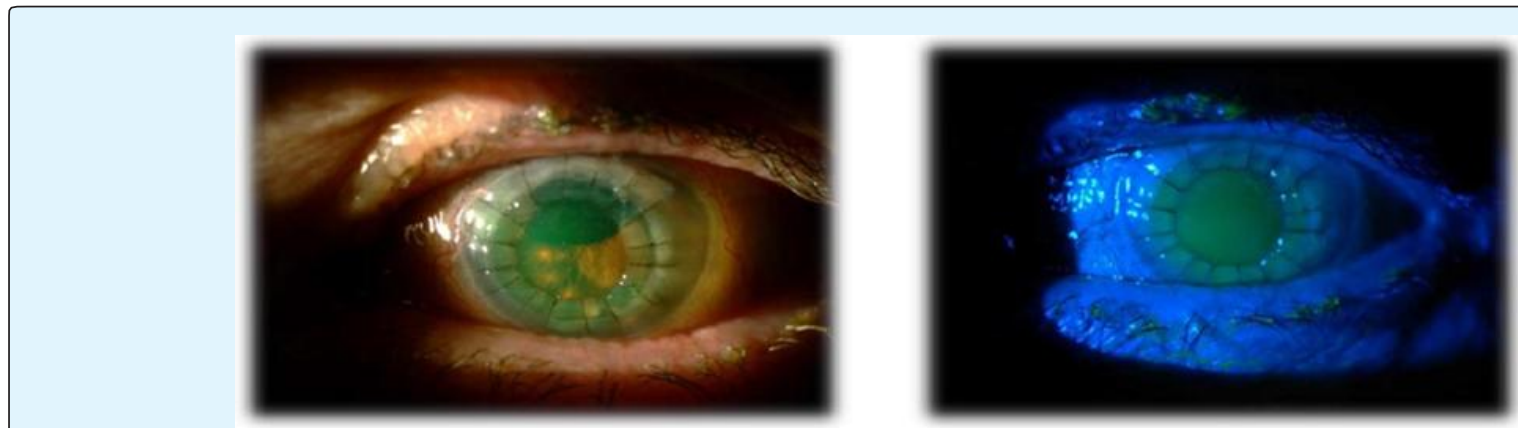

Figure 1: Slit-lamp images of the left eye (case 1) two weeks after PKP.
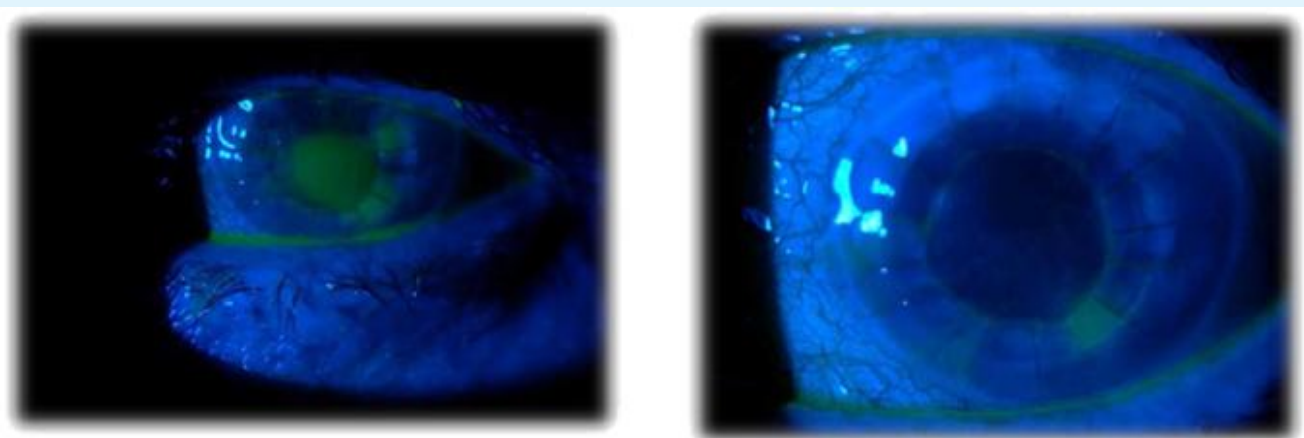

Figure 2: Slit-lamp images of the left eye (case 1) one week (A) and four weeks (B) after treatment with Cacicol ${ }^{20 .}$

\section{Case}

A 68-year-old man was referred to our department for the management of a corneal leukoma in his left eye which was caused by chronic trichiasis and a complicated cataract surgery. BCVA was 0,05 (Snellen scale) in this eye. He had undergone a PKP and after one week the examination showed an extended graft epithelial defect. The PED was resistant to conventional treatment for six weeks. Conventional therapy during
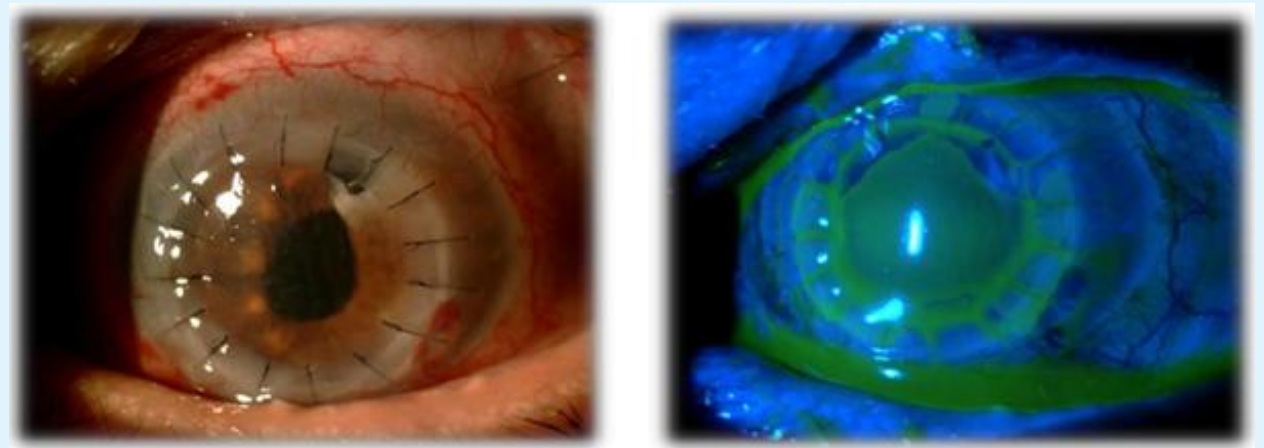

Figure 3: Slit-lamp images of the left eye (case 2) one day (A) and one week (B) after PKP. up, no recurrence was observed. this period included the use of contact lens, pressure patch, topical antibiotics and steroids, artificial tears and two amniotic membrane grafts. One week after Cacicol $^{20}$ application (instillation of 1 drop in alternate days) the dimensions of the epithelial defect decreased and five weeks later (six weeks after the treatment commenced), slit-lamp examination showed complete corneal epithelial healing. During the 6-month follow- 


\section{Open Access Journal of Ophthalmology}

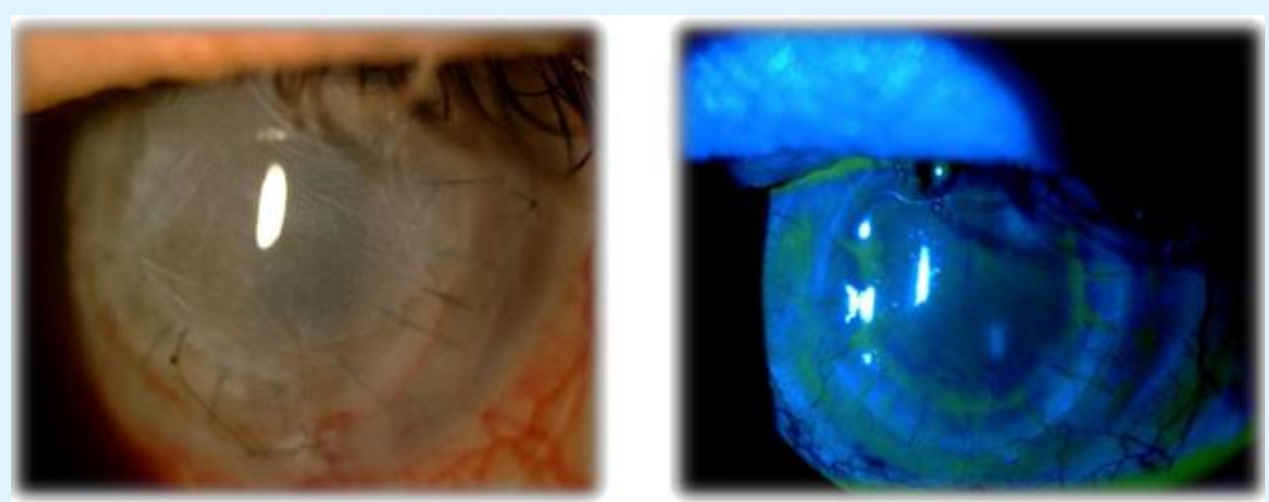

Figure 4: Slit-lamp images of the left eye (case 2) with amniotic membrane graft and contact lens (A) and six weeks (B) after treatment with $\mathrm{Cacicol}^{20}$.

\section{Discussion}

Managing the PED after PKP should be as fast as possible due to possible severe consequences which may occur. Besides that it can be both an arduous task for the ophthalmologist and a burden to the patient. Several approaches have been proposed for the treatment of PEDs such as artificial tears, eye patching, tarsorrhaphy, autologous serum eye drops, amniotic membrane graft and topical application of autologous limbal stem cells [610]. However, in some cases, these treatments (combined or not) tend to be ineffective thereby prolonging patient discomfort and their diminished visual acuity, as well as requiring frequent clinic follow-up at a cost to society and worker productivity.

RGTAs comprise a family of biodegradable glucose based polymers engineered to replace heparan sulfates [11]. RGTAs mimic the action of destroyed heparan sulfate molecules, break the negative repair-destruction cycle occurring in chronic lesions and inhibit proteolytic enzymes in vitro $[11,14]$. Cacicol ${ }^{20}$ has already been used as a monotherapy for the treatment of ocular surface disorders such as neurotrophic ulcers and keratitis [12,13]. Aifa et al. [12] reported corneal healing in 8 of 11 patients treated with an RGTA (Cacicol ${ }^{20}$ ) as mono therapy at a dosage of a single drop every 2 days, with 1 case of recurrence. This topical RGTA replaces the destroyed heparan sulfates and binds to matrix proteins to protect them from proteolysis; the extracellular matrix microenvironment protection improves the production of signals and growth factors needed for tissue healing [11].

In this article we report our experience in two patients who presented with a PED resistant for conventional treatment. These patients after topical instillation of RGTA $\left(\mathrm{Cacicol}^{20}\right.$ ) improved their clinical condition with complete corneal healing. However there was no

Sonia P. Topical Application of a Regenerative Agent for the Treatment of Persistent Epithelial Defects after Penetrating Keratoplasty. J Ophthalmol 2017, 2(1): 000113. improvement in BCVA. There were no RGTA-related local or systemic side effects.

\section{Conclusion}

In conclusion, our cases show revealed that topical application of $\mathrm{Cacicol}^{20}$ seems to be an effective alternative therapeutic approach for the treatment of PEDs after PKP. Nevertheless, further studies with a larger number of patients are needed to evaluate treatment potential.

\section{References}

1. Pfister RR (1992) Clinical measures to promote corneal epithelial healing. Acta Ophthalmol Suppl 202: 73-83.

2. Tsubota K, Goto E, Shimmura S, Shimazaki J (1999) Treatment of persistent corneal epithelial defect by autologous serum application. Ophthalmology 106(10): 1984-1989.

3. Wagoner MD, Ba-Abbad R, Al-Mohaimeed M, AlSwailem S, Zimmerman MB (2009) Postoperative complications after primary adult optical penetrating keratoplasty: prevalence and impact on graft survival. Cornea 28(4): 385-394.

4. Wilson SE, Kaufman HE (1990) Graft failure after penetrating keratoplasty. Survey of Ophthalmology 34(5): 325-356.

5. Constantinou M, Jhanji V, Tao LW, Vajpayee RB (2009) Clinical review of corneal ulcers resulting in evisceration and enucleation in elderly population. Graefes Arch Clin Exp Ophthalmol 247(10): 13891393. 


\section{Open Access Journal of Ophthalmology}

6. Jeng BH, Dupps WJ (2009) Autologous serum 50\% eye drops in the treatment of persistent corneal epithelial defects. Cornea 28(10): 1104-1108.

7. Lee SH, Tseng SC (1997) Amniotic membrane transplantation for persistent epithelial defects with ulceration. Am J Ophthalmol 123(3): 303-312.

8. Agorogiannis GI, Alexaki VI, Castana O, Kymionis GD (2012) Topical application of autologous adiposederived mesenchymal stem cells (MSCs) for persistent sterile corneal epithelial defect. Graefes Arch Clin Exp Ophthalmol 250(3): 455-457.

9. Bonini S, Lambiase A, Rama P, Caprioglio G, Aloe L (2000) Topical treatment with nerve growth factor for neurotrophic keratitis. Ophthalmology 107(7): 1347-1351.

10. Blackmore SJ (2010) The use of contact lenses in the treatment of persistent epithelial defects. Cont Lens Anterior Eye 33(5): 239-244.
11. Barritault D, Caruelle JP (2006) Regenerating agents (RGTAs): a new therapeutic approach. Ann Pharm Fr 64(2): 135-144.

12. Aifa A, Gueudry J, Portmann A, Delcampe A, Muraine $M$ (2012) Topical treatment with a new matrix therapy agent (RGTA) for the treatment of corneal neurotrophic ulcers. Invest Ophthalmol Vis Sci 53(13): 8181-8185.

13. Chebbi CK, Kichenin K, Amar N, Nourry H, Warnet JM et al. (2008) Pilot study of a new matrix therapy agent (RGTA OTRA4120) in treatment-resistant corneal ulcers and corneal dystrophy. J Fr Ophtalmol 31(5): 465-471.

14. Rouet V, Meddahi-Pellé A, Miao HQ Vlodavsky I, Caruelle JP et al. (2006) Heparin-like synthetic polymers, named RGTAs, mimic biological effects of heparin in vitro. J Biomed Mater Res A 78(4): 792797. 